\title{
Saline with methylene blue-assisted endoscopic ultrasound-guided gastro- jejunostomy using a double-flared fully covered metal stent
}
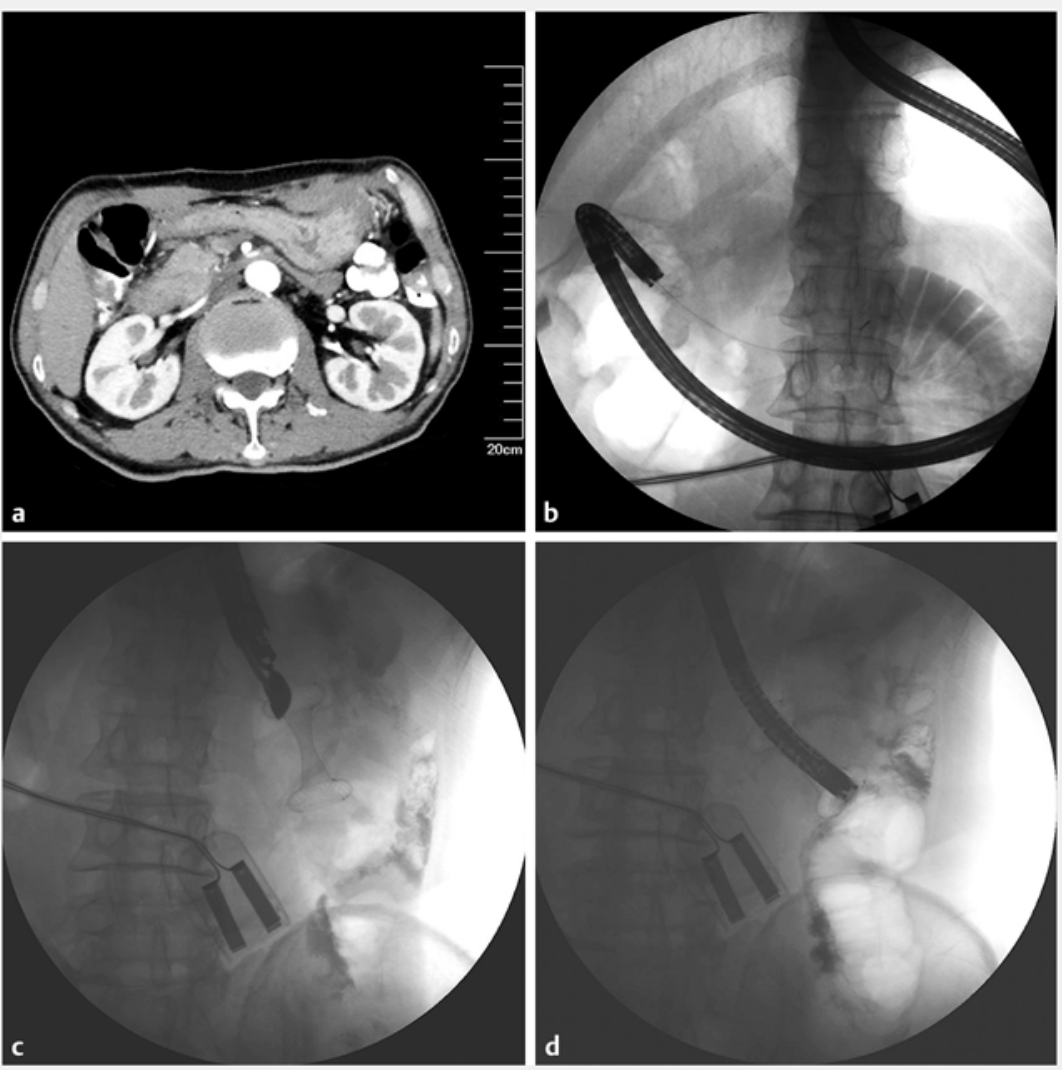

- Fig. 1 The stages of endoscopic ultrasound-guided gastrojejunostomy and stent placement. a Computed tomography showed a low-density $23 \times 17 \mathrm{~mm}$ mass in the pancreatic head (presumed to be pancreatic cancer), along with distal biliary obstruction, a dilated pancreatic duct, and multiple enlarged pancreatic, hilar, and hepatic lymph nodes. b Angiography showed the distal bowel. Then, the wire was removed and approximately $200 \mathrm{~mL}$ of saline with methylene blue dye was pumped into the distal small bowel through the catheter. c The guidewire was inserted through the needle lumen into the jejunum, the needle was removed over the wire, and the fully covered, double-flanged, metal stent was introduced and released. $\mathbf{d}$ Contrast agent was injected through the working channel and clearly showed the jejunum.

Duodenal malignant stenosis can be caused by primary duodenal cancer or pancreatic cancer involving the duodenum [1]. Current treatment options include laparoscopic bypass and palliative duodenal stent placement under endoscopic or radiographic guidance. Both methods have their advantages and disadvantages. Surgical methods will cause greater trauma to patients, while a duo-

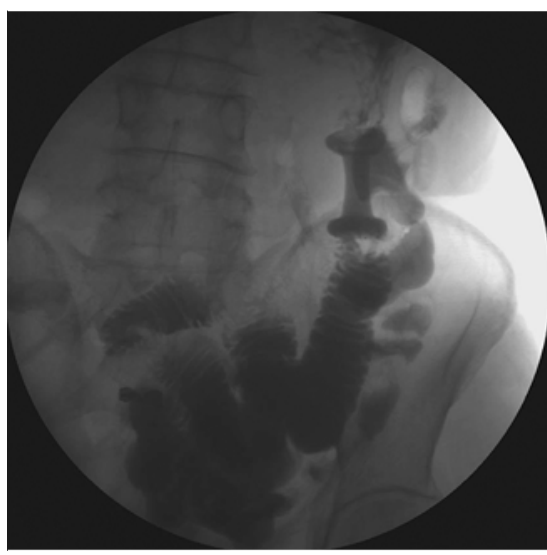

- Fig. 2 A computed tomography scan 4 days after the procedure confirmed that the stent was in a good position and that oral contrast agent passed easily from stomach to jejunum.

Here, we report a successful EUS-guided gastrojejunostomy (EUS-GJ) in a 65-yearold man who presented to our hospital with malignant duodenal stenosis, causing persistent vomiting and difficulty eating. Computed tomography (CT) showed a low-density $23 \times 17 \mathrm{~mm}$ mass in the pancreatic head (presumed to be pancreatic cancer), along with distal biliary obstruction, a dilated pancreatic duct, and multiple enlarged pancreatic, hilar, and hepatic lymph nodes ( $\mathbf{F i g} \mathbf{1} \mathbf{a}$ ). The patient had undergone a Roux-en-Y bypass 2 years previously at another hospital. The previous surgery precluded laparoscopic intervention because of abdominal adhesions; we therefore decided to perform EUS-G].

The patient was placed in a supine position under general anesthesia. The endoscope was advanced to the area of the stenosis, and a guidewire and catheter were inserted across the stenosis, which was too narrow for passage of the endoscope. Angiography showed the distal bowel. Then, the wire was removed and approximately $200 \mathrm{~mL}$ of saline with methylene blue dye was pumped into the distal small bowel through the catheter 


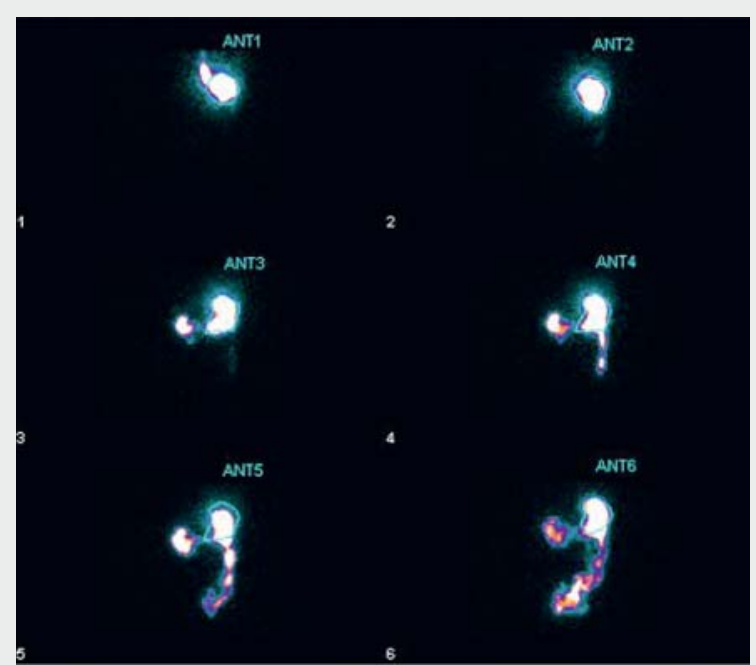

Anterior

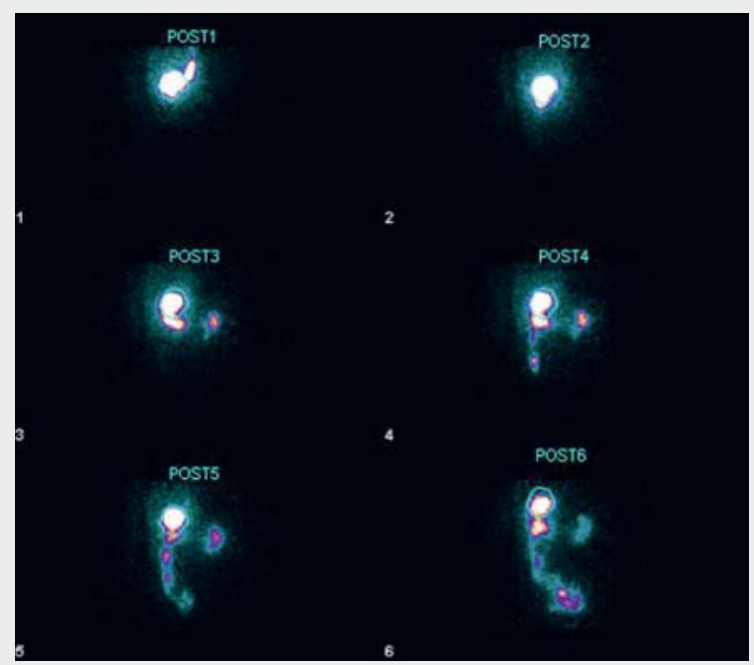

Posterior

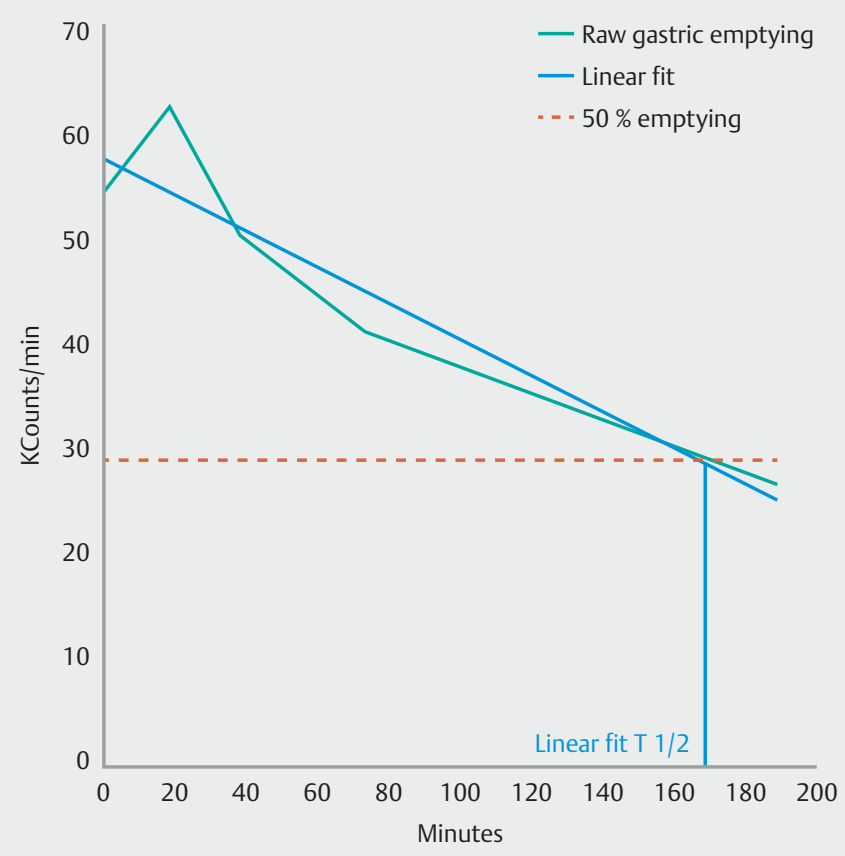

Decay Corrected by Xeleris: Yes

Linear fit $\mathrm{T} 1 / 2(\mathrm{~min})=169.28$

Linear fit slope $(\% / \mathrm{min})=0.30$

Raw data $\mathrm{T} 1 / 2(\mathrm{~min})=185.68$

Tc_99m

$\begin{array}{crrcccr}\text { Frame } & \text { Time } & \text { Fit } & \text { Raw \% empty } & \text { KCounts/min** } & \text { Anterior } & \text { Post } \\ 1 & 0.0 & 0 & 0 & 54.05 & 67.00 & 43.60 \\ 2 & 18.0 & 5 & -15 & 62.02 & 89.04 & 43.20 \\ 3 & 38.0 & 11 & 7 & 50.39 & 78.79 & 32.23 \\ 4 & 54.0 & 46 & 15 & 46.16 & 71.00 & 30.02 \\ 5 & 73.0 & 22 & 24 & 40.97 & 56.44 & 29.74 \\ 6 & 189.0 & 56 & 51 & 26.61 & 46.22 & 15.32\end{array}$

${ }^{* *}$ Geometric mean

- Fig. 3 Postprandial gastric emptying was evaluated after a meal of fried eggs and bread, and showed good function, with the meal passing into the jejunum through the stent.

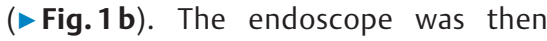
removed and a longitudinal echoendoscope, with a working channel of $3.8 \mathrm{~mm}$ (Pentax, Tokyo, Japan), was positioned at the posterior wall along the greater curvature of the stomach according to the preoperative CT image, which showed the proximal jejunum to be located outside the gastric wall. EUS visualization of the dilated bowel adjacent to the stomach was obtained. An Echo Tip Ultra EUS needle (19-G; Cook Medical Inc., Bloomington, Indiana, USA) was introduced via the working channel of the echoendoscope, and the wall of jejunum was punctured under EUS guidance. The blue fluid was aspirated to confirm that the needle was in the proximal jejunum, and contrast agent was then injected through the needle to show the jejunum. Next, the guidewire was inserted through the needle lumen into the jejunum, the needle was removed over the wire, and the fully covered, double-flanged, metal stent (16 mm/35 mm; Micro-Tech (Nanjing) Co., Ltd. Nanjing, China) was introduced and released ( $>$ Fig. $\mathbf{1}$ c). A large amount of blue fluid was seen rushing into the gastric cavity. Finally, the lumen of the deployed stent was dilated with a $12 \mathrm{~mm}$ columnar balloon dilator. The endoscope was passed through the stent into the jejunum after dilation of the stent. Contrast agent was injected through the working channel and clearly showed the jejunum ( Fig.1d). The patient received postoperative antibiotics and proton pump inhibitors, and did not develop fever or any sign of peritonitis.

A CT scan 4 days after the procedure confirmed that the stent was in a good position and that oral contrast agent passed easily from stomach to jejunum (> Fig.2). Upper gastrointestinal endoscopy with a standard endoscope on postoperative Day 5 showed that the stent was in place and was well opened, allowing passage of the endoscope from the stomach to the jejunum. Finally, postprandial gastric emptying was evaluated after a meal of fried eggs and bread, and 


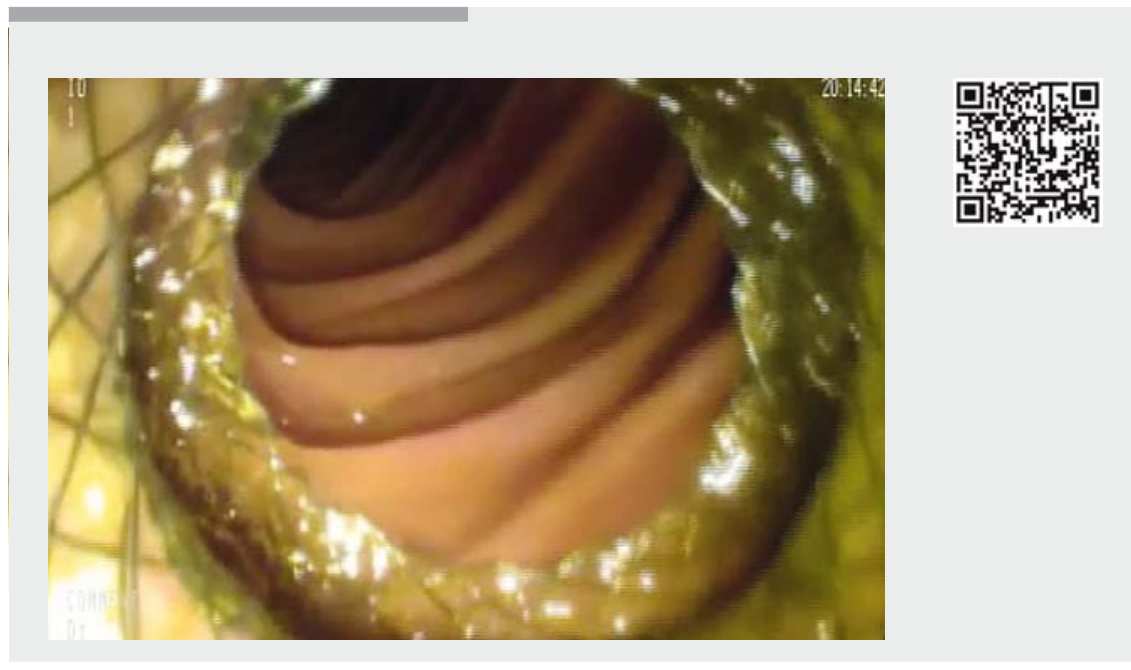

Video 1 Saline with methylene blue-assisted endoscopic ultrasound-guided gastrojejunostomy using a double-flared fully covered metal stent

showed good function, with the meal passing into the jejunum through the stent ( $\triangleright$ Fig. 3, $\triangleright$ Video 1 ).

As EUS techniques and related devices develop [3,4], various modalities of EUS-GE have received attention, including balloon-assisted methods and other techniques [5]. Here, we have described successful EUS-JE, in which saline with methylene blue was used to fill the jejunum in advance of the wall puncture. We found that this method was simple and fast, and we believe it is a useful new technique for EUS-GE.

\section{Endoscopy_UCTN_Code_TTT_1AS_2AG}

\section{Competing interests}

None

\section{Ge, Jintao Guo, Siyu Sun}

Endoscopy Center, Shengjing Hospital of China

Medical University, Shenyang, China

\section{Corresponding author}

\section{Sun Siyu, MD}

Endoscopy Center, Shengjing Hospital of China Medical University, 36 Sanhao Street, Heping District, Shenyang, Liaoning Province, China

sun-siyu@163.com

\section{Acknowledgment}

This study was supported by the National Natural Science Foundation of China (Grant No. 81470908).

[1] Barthet M, Binmoeller KF, Vanbiervliet G et al. Natural orifice transluminal endoscopic surgery gastroenterostomy with a biflanged lumen-apposing stent: first clinical experience (with videos). Gastrointest Endosc 2015; 81: 215-218

[2] Khashab MA, Kumbhari V, Grimm IS et al. EUS-guided gastroenterostomy: the first U.S. clinical experience (with video). Gastrointest Endosc 2015; 82: 932 - 938

[3] Sun B, Guo ], Ge N et al. Endoscopic ultrasound-guided puncture suture device versus metal clip for gastric defect closure after endoscopic full-thickness resection: a randomized, comparative, porcine study. Endosc Ultrasound 2016; 5: $263-268$

[4] Itoi T, Ishii K, Tanaka R et al. Current status and perspective of endoscopic ultrasonography-guided gastrojejunostomy: endoscopic ultrasonography-guided double-balloon-occluded gastrojejunostomy (with videos). J Hepatobiliary Pancreat Sci 2015; 22: $3-11$

[5] Itoi T, Ishii K, Ikeuchi N et al. Prospective evaluation of endoscopic ultrasonography-guided double-balloon-occluded gastrojejunostomy bypass (EPASS) for malignant gastric outlet obstruction. Gut 2016; 65: 193-195

\section{Bibliography}

DOI https://doi.org/10.1055/s-0043-119981

Published online: 25.10.2017

Endoscopy 2018; 50: E17-E19

(c) Georg Thieme Verlag KG

Stuttgart · New York

ISSN 0013-726X

\section{ENDOSCOPY E-VIDEOS}

https://eref.thieme.de/e-videos

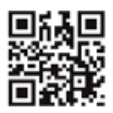

Endoscopy E-Videos is a free access online section, reporting on interesting cases and new techniques in gastroenterological endoscopy. All papers include a high quality video and all contributions are freely accessible online.

This section has its own submission website at https://mc.manuscriptcentral.com/e-videos 